\title{
Comparison of Multi-Criteria Decision Making Methods for Multi Optimization of GTAC Process Parameters
}

\author{
Rajeev Ranjan ${ }^{1,3}$, Abhijit Saha $^{2 *}$, Anil Kumar Das ${ }^{3}$ \\ 1 Department of Mechanical Engineering, Dr. B.C. Roy Engineering College, 713206 Durgapur, West Bengal,India \\ 2 Department of Mechanical Engineering, Haldia Institute of Technology, 721657 Haldia, West Bengal, India \\ ${ }^{3}$ Department of Mechanical Engineering, National Institute of Technology, 800005 Patna, Bihar, India \\ * Corresponding author, e-mail: alfa.nita2010@gmail.com
}

Received: 11 January 2022, Accepted: 03 February 2022, Published online: 18 February 2022

\begin{abstract}
A great deal of investigation on gas tungsten arc cladding (GTAC) is focused on the study of enhancements in the microstructure, mechanical and tribological features of the cladding. The selection of right process parameters is a critical issue for the researchers. Decision makers in the industries must analyze a wide variety of parameters based on a set of contradictory criteria. Several multicriteria decision-making (MCDM) techniques are now available to add values in selection of these parameters. The application of the TOPSIS and MOORA techniques to identify the best configuration of processing parameters in the gas tungsten arc cladding (GTAC) process is investigated in this work. The best processing parameters set for the multiple performance attributes should be welding current: 70 amp, speed: 240, argon flow: 13 and stand off distance 3.5 (TOPSIS-PCA) and welding current: 50, speed: 300, argon flow: 13 and standoff distance 3.5 (MOORA-PCA).A comparison of MOORA-PCA and TOPSIS-PCA demonstrates the superiority of TOPSIS over MOORA technique. The prediction accuracy of the TOPSIS-PCA hybrid approach model is found better than MOORA-PCA technique. Keywords
\end{abstract}

GTAC, MCDM, TOPSIS, MOORA, PCA

\section{Introduction}

Wear, corrosion, fracture, and oxidation caused machine elements to weaken and fractured early in their intended lifespan. These are common issues in a wide range of industries, including mining, mineral processing, manufacturing, and agriculture. The degradation of component surfaces is caused by wear and corrosion, resulting in downtime and greater manufacturing costs. When operating on hard surfaces, agricultural instruments, mining machinery, and earthmoving machinery face the same difficulty. Similarly, machinery in the chemical and petroleum industries are prone to corrosion. The weld cladding techniques can be used to boost the service life of wear and corrosion prone elements at a minimal cost by modifying their functional surfaces.There are various distinct types of weld cladding processes available today, each with its own set of benefits. Weld cladding is done by different methods like gas tungsten arc cladding (GTAC), laser cladding, and plasma cladding processes. Weld cladding has been applied in a variety of industrial uses, and there have been several advancements in this field over the last decade. There were a lot of studies done targeting GTAC because of its advantages such as user-friendly, low cost, high deposition rate, low dilution, high reliability, etc. Based on Fig. 1, we can easily understand the importance of GTAC, which indicates a decade-wise increasing graph of $\%$ of research articles referred to under this domain.

In the GTAC process, the heat generated by the electric arc between the substrate and the tungsten electrode is used to melt the coating materials as well as the substrate. It is an effective weld cladding process for stainless steel. Keeping process parameters within acceptable limits could result in a high-quality clad layer as discussed by Ranjan and Das [1]. Waghmare et al. [2] experimentally revealed that the hardness and wear characteristics of the cladding depend on the welding current. Das et al. [3] evaluated the hardness and wear resistance of a TiC - Fe composite cladding produced on steel AISI 1020. They looked at how input parameters affected the microstructure and hardness of the clad. They found decrease in hardness by increasing welding current. Singh et al. [4] studied 


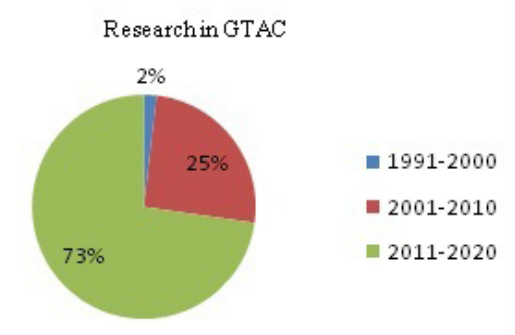

Fig. 1 Decade-wise distribution of \% of papers in Gas Tungsten Arc Cladding (GTAC) technique

the effect of the input variables, like welding current and speed over the microstructural changes. Solidification time varies due to variations in the welding current and speed, which results in a different kind of microstructure. They concluded that the GTA cladding developed at low heat input forms a cladding with higher hardness and wear resistance. Singh et al. [5]revealed that the wear resistance and hardness of cladding were mainly influenced by current applied followed by welding travel speed, standoff distance, and flow rate of shielding inert gases. Lima et al. [6]showed enhancement in the wear and corrosive properties of the coating. Kumar et al. [7] studied experimentally and revealed better adhesion between $\mathrm{Fe}-\mathrm{SiC}$ and SS304 substrate with improvement in anti-abrasive properties with higher microhardness.

Criteria, criteria weights and alternatives are commonly seen in a conventional MCDM issue. Two MCDM approaches were used in this research, and their findings are presented here. For the chemical-mechanical polishing of copper thin films, Tong et al. [8] used the TOPSIS -PCA approach. For process improvement in FSW of Aluminium Alloy, Sudhagar et al. [9] used a multi-criteria decision-making technique called GRA and TOPSIS. Saha and Mondal [10] employed a hybrid PCA-TOPSIS approach to optimise MMAW process parameters for multi-objective optimization. MOORA (multi-objective optimization based on ratio analysis) is reported to be very easy to use and understand theoretically by Majumder and Maity [11]. Khan et al. [12] successfully applied the MOORA approach to a variety of non-traditional processes, describing the process as simple to operate, time efficient, and exact. Apart from non-traditional machining processes, the MOORA technique has been successfully applied to optimise a variety of other production processes such as milling [13], turning [14], welding [15], and so on.

Most researchers have successfully used the MCDM technique to tackle the sequence of process parameter selection problem. Following a thorough study of the literature, it was discovered that application of MCDM methods for multi optimization of GTAC process parameters is an untouched area of research. TOPSIS and MOORA techniques have also been proved to be successful in identifying and selecting the optimal material for a given product in the research mentioned above. As a result, the goal of this study is to find the optimal combination of processing parameters in GTAC process using MOORA and TOPSIS. Moreover, comparative study between these two methods has been done.

\section{Materials and methods}

The MCDM (Multi-Criteria Decision Making) and optimization procedures are part of the Material Selection Methodology.

\subsection{MOORA method}

Brauers and Zavadskas [16] was the first to introduce a robust decision-making technique called MOORA. It is applied in following steps:

1. Step 1: determine the issue.

Establish the aim and list all possible choices together with their attributesare the first step to applied MOORA.

2. Step 2: create a decision- matrix.

MOORA's next step, like any multi-objective optimization approach, is to create the decision matrix after recognizing the objectives and alternatives:

$$
A=\left[\begin{array}{ccccc}
a_{11} & a_{12} & \ldots & \ldots & a_{1 n} \\
a_{21} & a_{22} & \ldots & \ldots . & a_{2 n} \\
\ldots & \ldots . & \ldots & \ldots & \ldots . \\
\ldots & \ldots . & \ldots & \ldots & \ldots . \\
a_{m 1} & a_{m 2} & \ldots & \ldots . & a_{m m}
\end{array}\right],
$$

where:

- $a_{i j:}$ performance quantity of the $i^{\text {th }}$ alternative on $j^{\text {th }}$ response;

- $n$ : number of attributes;

- $\mathrm{m}$ : number of alternatives.

3. Step 3 normalize the performance measures.

Normalization is usually done on the basis of Eq. (2):

$$
a_{i j}^{*}=\frac{a_{i j}}{\sqrt{\sum_{i=1}^{m} a_{i j}{ }^{2}}}(j=1,2, \ldots, n),
$$

where:

- $a_{i j}^{*}$ : normalized value $i^{\text {th }}$ alternative on $j^{\text {th }}$ criteria $\left(0<a_{i j}^{*}<1\right)$. 
4. Step 4: evaluation of the total evaluation value.

Based on previous literature, overall assessment of the performance measure can be defined as:

$y_{i}=\sum_{j=1}^{g} a_{i j}^{*}-\sum_{j=g+1}^{n} a_{i j}^{*}$

where:

- $y_{i}$ represents the normalized assessment value of the $i^{\text {th }}$ option across all characteristics;

- $g$ represents the attributes number to be maximized;

- and $(n-g)$ represents the attributes number to be reduced.

It is considered that every response in a system has not the same effect; some are more dominating than others. Any response might thus be multiplied with its associated weight to give it greater relevance. In this case, the entire evaluation value is as follows:

$y_{i}=\sum_{j=1}^{g} w_{j} a_{i j}^{*}-\sum_{j=g+1}^{n} w_{j} a_{i j}^{*}$

where $w_{j}$ : weight of $j^{\text {th }}$ criteria.

5. Step 5: allocate ranking to the overall assessment. The total assessment scores are then ranked in descending order, with the greatest value of $y_{i}$ indicating the best alternate and the lowest value of $y_{i}$ indicating the worst.

\subsection{Principal Component Analysis (PCA)}

Pearson [17] introduced the PCA statistical analysis technique in 1901. It is started with an array of $n$-experiments and $m$-characteristics in a multi-response mode. The correlation coefficient is then calculated using Eq. (5):

$$
R_{j l}=\frac{\operatorname{cov}\left(x_{i}(j), x_{i}(l)\right)}{\sigma x_{i}(j) * \sigma x_{i}(l)},
$$

where:

- $x_{i}(j)$ are the response's normalized values;

- $\sigma x_{i}(j)$ and $\sigma \mathrm{x}_{i}(l)$ are the standard deviations of the response variables $j$ and $l$, respectively;

- $\operatorname{cov}\left(x_{i}(j), x_{i}(l)\right)$ : response variable $j$ and $l$ covariance.

As a result, Eigen values and their related eigenvectors are:

$$
\left(R-\lambda_{x} I_{m}\right) V_{i k}=0,
$$

where:

- $\lambda_{x}$ : Eigen values;

- $\sum_{k=1}^{n} \lambda_{k}=n$

- $k=1,2, \ldots, n$;

- $V_{i k}\left[a_{k 1}, a_{k 2}, \ldots, a_{k m}\right]^{\mathrm{T}}$ : Eigen vectors corresponding to Eigen value $\lambda_{k}$.

Thus, the principal components are:

$Y_{m k}=\sum_{i=1}^{n} x_{m}(i) V_{i k}$,

where:

- $Y_{m 1}$ : stands for the first main component.

- $Y_{m 2}:$ The second major component, and so on.

In decreasing order, the primary components are sorted in terms of variance.

\subsection{TOPSIS method}

The approach consists of the following steps as discussed by Saha and Mondal [10]:

1. Step 1: the characteristic values of alternatives at attributes ( $\mathrm{S} / \mathrm{N}$ ratios for responses were computed) $\left(\eta_{i j} ; I=1,2 \ldots\right.$ number of experiments $(m)$, $j=1,2 \ldots$ number of responses $(n))$ are inputted into the TOPSIS programme and stored in matrix form as stated in Eq. (4):

$$
D=\left[\begin{array}{llll}
\eta_{11} & \eta_{12} & \ldots . & \eta_{1 n} \\
\eta_{21} & \eta_{22} & \ldots . & \eta_{2 n} \\
\ldots . & \ldots . & \ldots . & \ldots . \\
\eta_{m 1} & \eta_{m 2} & \ldots . & \eta_{m n}
\end{array}\right] .
$$

2. Step 2: the vector normalization method is used to calculate normalized values:

$$
r_{i j}=\frac{\eta_{i j}}{\sqrt{\sum_{i=1}^{m} \eta_{i j}^{2}}}
$$

where $r_{i j}$ denotes the normalized value of the $j^{\text {th }}$ criterion's $i^{\text {th }}$ alternative, which is between 0 and 1 .

3. Step 3: calculate the normalized weighted decision matrix. The following formula is used to calculate the weighted normalized value $v_{i j}$ :

$$
v_{i j}=r_{i j} \times w_{j},
$$


where $w_{j}$ is the weight of the $j^{\text {th }}$ criterion or attribute and $\sum_{j=1}^{n} w_{j}=1$.

4. Step 4: find out the ideal $\left(A^{*}\right)$ and negative ideal $\left(A^{-}\right)$ solutions.

The positive ideal solution, $A^{*}(i=1,2, \ldots, m)$, is made of all the best values and the negative-ideal solution, $A^{*}(i=1,2, \ldots, m)$, is made of all the worst values at the responses in the weighted normalized decision matrix $\left(v_{i j}\right)$. They are calculated by using Eqs. (10) and (11):

$$
\begin{aligned}
& A^{*}=\left\{\left(\max _{i} v_{i j} \mid j \in C_{b}\right),\left(\max _{i} v_{i j} \mid j \in C_{c}\right)\right\}= \\
& \left\{v_{j}^{*} \mid j=1,2, \ldots, m\right\}, \\
& A^{-}=\left\{\left(\min _{i} v_{i j} \mid j \in C_{b}\right),\left(\min _{i} v_{i j} \mid j \in C_{c}\right)\right\}= \\
& \left\{v_{j}^{-} \mid j=1,2, \ldots, m\right\} .
\end{aligned}
$$

5. Step 5: using the m-dimensional Euclidean distance, calculate the separation measurements. Equations (13) and (14) are the separation measures between each alternative and the positive and negative ideal solutions, respectively:

$$
\begin{aligned}
& S_{i}^{*}=\sqrt{\sum_{j=1}^{m}\left(v_{i j}-v_{j}^{*}\right)^{2}}, \\
& S_{i}^{-}=\sqrt{\sum_{j=1}^{m}\left(v_{i j}-v_{j}^{-}\right)^{2}},
\end{aligned}
$$

where $j=1,2, \ldots, m$.

6. Step 6: determine how near the solution is to the ideal. It is defined as follows:

$$
R C_{i}^{*}=\frac{S_{i}^{-}}{S_{i}^{*}+S_{i}^{-}}
$$

where $i=1,2, \ldots, m$.

7. Step 7: sort the preferences in ascending order.

\section{Results and discussion}

To demonstrate and validate the effectiveness of MOORA and TOPSIS method, author's has considered the practical example of cladding process from the literature [4].

\subsection{Principal Component Analysis (PCA)}

The relative weights of each performance metric were computed using the PCA technique, according to Eq. (6). Following PCA, the weightage for micro hardness and wear are 0.4998 and 0.4998 , respectively, indicating that within the studied input parameter range, both qualities are equally essential.

\subsection{MOORA-PCA: Hybrid approach}

Welding current, speed, argon flow, and standoff distance are among the parameters investigated in this study andattributesaremicro hardness and wear. The main aim was to maximize the micro hardness and to minimize the wear.The decision matrix for the first step of the MOORA-PCA approach is represented in Table 1 with the final two columns (micro hardness and wear), in addition to the experiment numbers.

The values of performance characteristics are normalized to convert dimensional attributes to non-dimensional attributes. Equation (2) is used to calculate the normalized values of both qualitiesin all experimental run (refer Table 2).

The overall assessment value was determined using Eq. (4). Individual parameter settings have been ranked using the hybrid MOORA-PCA approach. Experiment no. 20 has the greatest value after being sorted in descending order. Fig. 2 shows there was reverse relation between total assessment values and multiple quality characteristics. As a result, the best combinations of process parameters are welding current: 50, speed: 300, argon flow: 13 and standoff distance 3.5 respectively.

\subsection{Multi-response optimization: TOPSIS - PCA hybrid approach}

Equation (13) is used to calculate weighted normalized values of both quality attributes in all experimental run (Table 3). The relative weights of each performance characteristic were then analyzed using the principal component analysis approach according to Eq. (7), then using Eqs. (11) and (12), positive ideal solutions $\left(A^{*}\right)$ and negative ideal solutions $\left(A^{-}\right)$were calculated. Finally, Table 3 shows similarity of the ideal solutions in each case calculated using Eq. (15). Each evaluated value has been allocated a rating using the TOPSIS approach after being arranged in decreasing order. Experiment 23 was discovered to have the greatest value. Fig. 3 shows that the closer the solution was to the ideal, the better the multiple quality characteristics were. As a result, the best combinations of process parameters are welding current: $70 \mathrm{amp}$, speed: 240, argon flow: 13 and standoff distance 3.5 respectively.

\section{Comparative study between two methods}

To construct a mathematical link between the various input factors and outcomes, the response surface methodology (RSM) was used. A quadratic model for the 
Table 1 Experimental findings and design matrix

\begin{tabular}{|c|c|c|c|c|c|c|}
\hline $\begin{array}{l}\text { Exp. } \\
\text { No. }\end{array}$ & $\begin{array}{l}\text { Welding } \\
\text { current }\end{array}$ & $\begin{array}{c}\text { Welding } \\
\text { speed }\end{array}$ & $\begin{array}{c}\text { Argon } \\
\text { flow }\end{array}$ & $\begin{array}{l}\text { Standoff } \\
\text { distance }\end{array}$ & $\begin{array}{c}\text { Micro } \\
\text { hardness }\end{array}$ & Wear \\
\hline 1 & 70 & 240 & 11 & 2.5 & 1030 & 16.1 \\
\hline 2 & 60 & 210 & 12 & 2 & 1020 & 18.4 \\
\hline 3 & 70 & 240 & 11 & 2.5 & 997 & 16.3 \\
\hline 4 & 60 & 270 & 12 & 3 & 1150 & 12.2 \\
\hline 5 & 60 & 270 & 10 & 2 & 1173 & 13 \\
\hline 6 & 50 & 240 & 11 & 2.5 & 1123 & 14.3 \\
\hline 7 & 70 & 240 & 13 & 2.5 & 1160 & 14.7 \\
\hline 8 & 80 & 210 & 12 & 2 & 920 & 20.2 \\
\hline 9 & 90 & 240 & 11 & 2.5 & 791 & 23.5 \\
\hline 10 & 80 & 210 & 10 & 3 & 944 & 19.5 \\
\hline 11 & 70 & 180 & 11 & 2.5 & 706 & 22.9 \\
\hline 12 & 80 & 210 & 12 & 3 & 1102 & 17.8 \\
\hline 13 & 70 & 240 & 11 & 1.5 & 1024 & 16 \\
\hline 14 & 80 & 270 & 10 & 3 & 1005 & 16.8 \\
\hline 15 & 80 & 270 & 12 & 3 & 1070 & 15 \\
\hline 16 & 60 & 270 & 12 & 2 & 1174 & 14.6 \\
\hline 17 & 60 & 210 & 12 & 3 & 1090 & 16.5 \\
\hline 18 & 70 & 240 & 9 & 2.5 & 982 & 20.1 \\
\hline 19 & 80 & 210 & 10 & 2 & 723 & 22.5 \\
\hline 20 & 70 & 240 & 11 & 3.5 & 1222 & 13.2 \\
\hline 21 & 70 & 240 & 11 & 2.5 & 1055 & 16.9 \\
\hline 22 & 60 & 210 & 10 & 3 & 1044 & 15.9 \\
\hline 23 & 80 & 270 & 10 & 2 & 920 & 22.3 \\
\hline 24 & 60 & 210 & 10 & 2 & 904 & 19.8 \\
\hline 25 & 70 & 300 & 11 & 2.5 & 1088 & 15.8 \\
\hline 26 & 80 & 270 & 12 & 2 & 950 & 17.5 \\
\hline 27 & 60 & 270 & 10 & 3 & 1089 & 13.4 \\
\hline
\end{tabular}

Table2 Final results

\begin{tabular}{|c|c|c|c|c|}
\hline \multirow{2}{*}{ Exp. No. } & \multicolumn{2}{|c|}{ Normalized values } & \multirow{2}{*}{$y_{i}$} & \multirow{2}{*}{ Rank } \\
\hline & Micro hardness & Wear & & \\
\hline 1 & 0.193 & 0.177 & 0.016 & 12 \\
\hline 2 & 0.192 & 0.202 & -0.011 & 18 \\
\hline 3 & 0.187 & 0.179 & 0.008 & 16 \\
\hline 4 & 0.216 & 0.134 & 0.082 & 2 \\
\hline 5 & 0.220 & 0.143 & 0.077 & 3 \\
\hline 6 & 0.211 & 0.157 & 0.054 & 7 \\
\hline 7 & 0.218 & 0.162 & 0.056 & 6 \\
\hline 8 & 0.173 & 0.222 & -0.049 & 23 \\
\hline 9 & 0.149 & 0.258 & -0.110 & 25 \\
\hline 10 & 0.177 & 0.214 & -0.037 & 21 \\
\hline 11 & 0.133 & 0.252 & -0.119 & 27 \\
\hline 12 & 0.207 & 0.196 & 0.011 & 15 \\
\hline 13 & 0.192 & 0.176 & 0.016 & 13 \\
\hline 14 & 0.189 & 0.185 & 0.004 & 17 \\
\hline 15 & 0.201 & 0.165 & 0.036 & 8 \\
\hline 16 & 0.220 & 0.160 & 0.060 & 4 \\
\hline 17 & 0.205 & 0.181 & 0.023 & 10 \\
\hline 18 & 0.184 & 0.221 & -0.037 & 20 \\
\hline 19 & 0.136 & 0.247 & -0.112 & 26 \\
\hline 20 & 0.229 & 0.145 & 0.084 & 1 \\
\hline 21 & 0.198 & 0.186 & 0.012 & 14 \\
\hline 22 & 0.196 & 0.175 & 0.021 & 11 \\
\hline 23 & 0.173 & 0.245 & -0.072 & 24 \\
\hline 24 & 0.170 & 0.218 & -0.048 & 22 \\
\hline 25 & 0.204 & 0.174 & 0.031 & 9 \\
\hline 26 & 0.178 & 0.192 & -0.014 & 19 \\
\hline 27 & 0.204 & 0.147 & 0.057 & 5 \\
\hline
\end{tabular}

\section{Main Effects Plot for Overall assessment value}

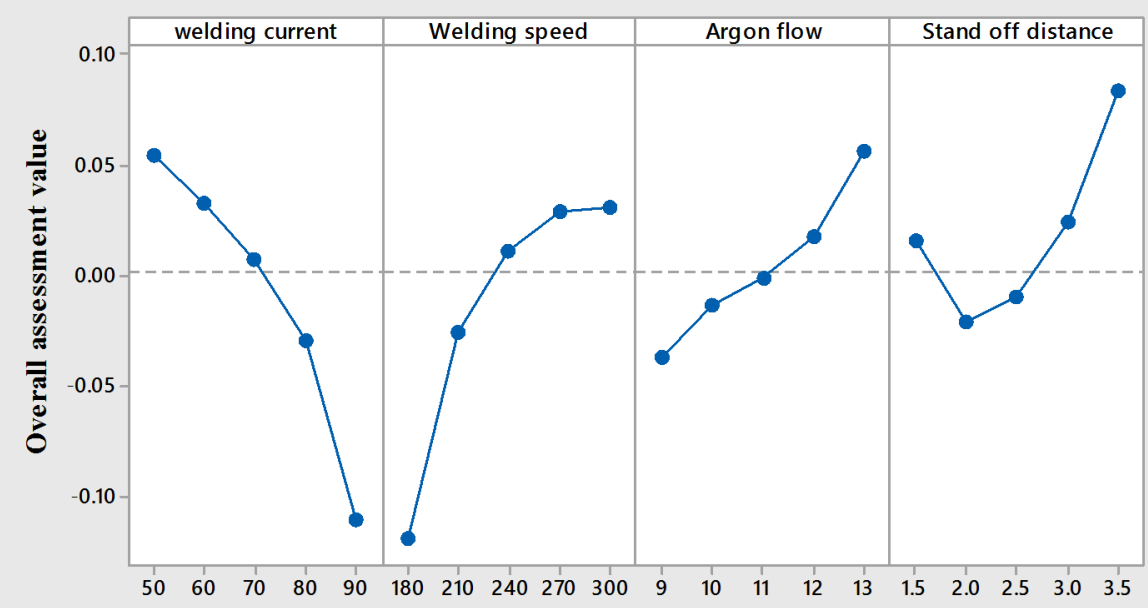

Fig. 2 Overall assessment value graph 
Table 3 Weighted normalized values, closeness coefficient values and ranking of alternatives

\begin{tabular}{|c|c|c|c|c|c|c|}
\hline \multirow{2}{*}{ Exp. No. } & \multicolumn{2}{|c|}{ Weighted normalized } & \multirow{2}{*}{$S_{i}^{*}$} & \multirow{2}{*}{$S_{i}^{-}$} & \multirow{2}{*}{$R C_{i}^{*}$} & \multirow{2}{*}{ Rank } \\
\hline & Micro hardness & Wear & & & & \\
\hline 1 & 0.193 & 0.177 & 0.089 & 0.298 & 0.770 & 14 \\
\hline 2 & 0.192 & 0.202 & 0.068 & 0.260 & 0.794 & 5 \\
\hline 3 & 0.187 & 0.179 & 0.090 & 0.299 & 0.770 & 15 \\
\hline 4 & 0.216 & 0.134 & 0.125 & 0.353 & 0.739 & 27 \\
\hline 5 & 0.220 & 0.143 & 0.116 & 0.340 & 0.746 & 26 \\
\hline 6 & 0.211 & 0.157 & 0.103 & 0.321 & 0.757 & 23 \\
\hline 7 & 0.218 & 0.162 & 0.097 & 0.312 & 0.762 & 20 \\
\hline 8 & 0.173 & 0.222 & 0.067 & 0.259 & 0.794 & 4 \\
\hline 9 & 0.149 & 0.258 & 0.081 & 0.284 & 0.779 & 10 \\
\hline 10 & 0.177 & 0.214 & 0.068 & 0.261 & 0.793 & 6 \\
\hline 11 & 0.133 & 0.252 & 0.097 & 0.312 & 0.762 & 19 \\
\hline 12 & 0.207 & 0.196 & 0.067 & 0.258 & 0.795 & 3 \\
\hline 13 & 0.192 & 0.176 & 0.090 & 0.301 & 0.769 & 17 \\
\hline 14 & 0.189 & 0.185 & 0.084 & 0.290 & 0.775 & 12 \\
\hline 15 & 0.201 & 0.165 & 0.098 & 0.313 & 0.762 & 21 \\
\hline 16 & 0.220 & 0.160 & 0.098 & 0.313 & 0.761 & 22 \\
\hline 17 & 0.205 & 0.181 & 0.081 & 0.284 & 0.779 & 9 \\
\hline 18 & 0.184 & 0.221 & 0.059 & 0.242 & 0.805 & 2 \\
\hline 19 & 0.136 & 0.247 & 0.094 & 0.307 & 0.765 & 18 \\
\hline 20 & 0.229 & 0.145 & 0.113 & 0.336 & 0.748 & 24 \\
\hline 21 & 0.198 & 0.186 & 0.079 & 0.281 & 0.781 & 8 \\
\hline 22 & 0.196 & 0.175 & 0.090 & 0.300 & 0.769 & 16 \\
\hline 23 & 0.173 & 0.245 & 0.058 & 0.241 & 0.806 & 1 \\
\hline 24 & 0.170 & 0.218 & 0.072 & 0.269 & 0.788 & 7 \\
\hline 25 & 0.204 & 0.174 & 0.088 & 0.297 & 0.771 & 13 \\
\hline 26 & 0.178 & 0.192 & 0.083 & 0.289 & 0.776 & 11 \\
\hline 27 & 0.204 & 0.147 & 0.114 & 0.337 & 0.748 & 25 \\
\hline
\end{tabular}

Main Effects Plot for Overall assessment value

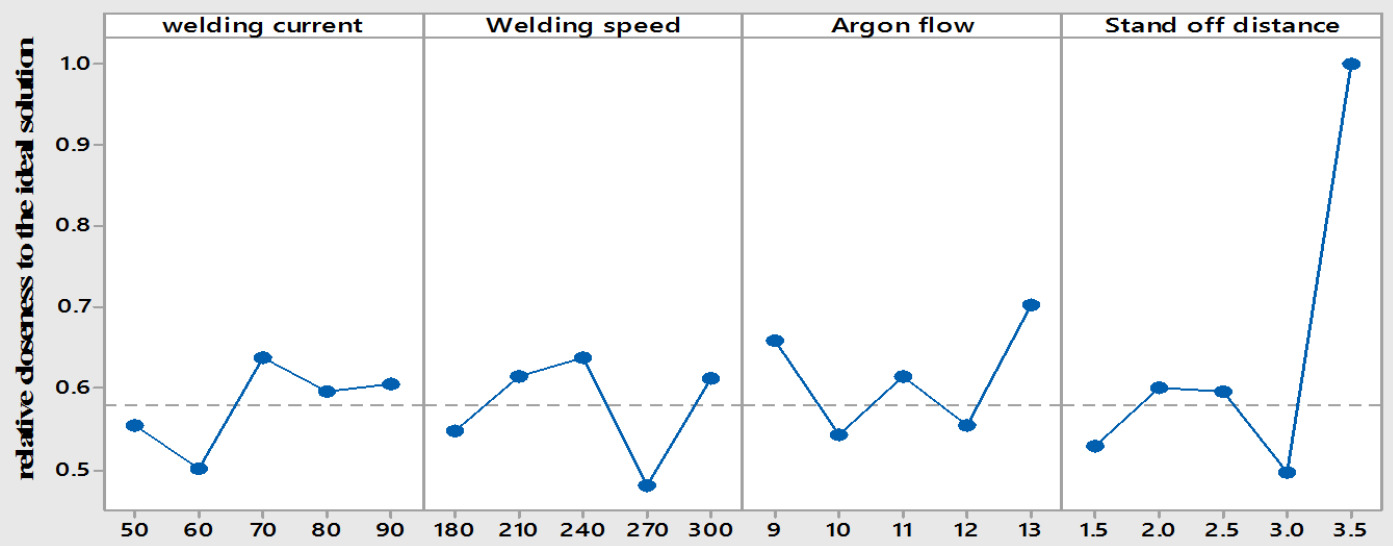

Fig. 3 Overall assessment value graph 
response surface was created to investigate the impact of several factors on the overall assessment value. The model coefficients were evaluated using MINITAB 17 and the least square approach. Equations (16) and (17) may be used to represent the projected quadratic model to predict the above stated hybrid approaches across the experimental region.

Equation (16) represents the quadratic model for the hybrid MOORA-PCA and Eq. (17) represents the quadratic model for the hybrid TOPSIS-PCA.

$$
\begin{aligned}
\text { Overall assessment value }= & -1.430+0.00148 \text { welding current }+0.01258 \text { welding speed } \\
& -0.0168 \text { Argon flow }-0.144 \text { stand off distance } \\
& -0.000092 \text { welding current* welding current } \\
& -0.000015 \text { welding speed } * \text { welding speed } \\
& +0.00019 \text { Argon flow* Argon flow } \\
& +0.0412 \text { stand off distance* stand off distance } \\
& -0.000031 \text { welding current } * \text { welding speed } \\
& +0.000962 \text { welding current* Argon flow } \\
& +0.001950 \text { welding current* stand off distance } \\
& -0.000108 \text { welding speed } * \text { Argon flow } \\
& -0.000458 \text { welding speed } * \text { stand off distance } \\
& -0.00425 \text { Argon flow } * \text { stand off distance }
\end{aligned}
$$

$$
\begin{aligned}
\text { Relative closeness value }= & 0.654-0.00272 \text { welding current }+0.00126 \text { welding speed } \\
& -0.0103 \text { Argon flow }+0.117 \text { stand off distance } \\
& -0.000005 \text { welding current* welding current } \\
& -0.000001 \text { welding speed } * \text { welding speed } \\
& +0.00333 \text { Argon flow } * \text { Argon flow } \\
& -0.0117 \text { stand off distance } * \text { stand off distance } \\
& +0.000023 \text { welding current * welding speed } \\
& -0.000213 \text { welding current* Argon flow } \\
& +0.000475 \text { welding current* stand off distance } \\
& -0.000175 \text { welding speed } * \text { Argon flow } \\
& -0.000250 \text { welding speed } * \text { stand off distance } \\
& -0.00375 \text { Argon flow } * \text { stand off distance }
\end{aligned}
$$

For both of the above approaches, error and average error are generated to assess the accuracy of the prediction model Table 4. The greatest prediction error for the MOORA-PCA hybrid approach is $12.5 \%$, whereas the same is $2.8 \%$ for the hybrid TOPSIS-PCA method. The average percentage error for the MOORA-PCA hybrid approach is $5.82 \%$, whereas it is $1.085 \%$ for advanced TOPSIS-PCA. In comparison to the MOORA-PCA technique, the prediction accuracy of the TOPSIS-PCA hybrid approach model proved to be more acceptable.

\section{Conclusions}

The findings were optimized using a hybrid optimization technique, MOORA-PCA and TOPSIS-PCA, simultaneously. Following are some possible conclusions based on the research findings:

- Welding current: 50, speed: 300, argon flow: 13, and standoff distance: 3.5 were determined to be the best combination for the hybrid MOORA-PCA method. For the hybrid TOPSIS-PCA technique, the best combination is current: $70 \mathrm{amp}$, speed: 240, argon flow: 13 , and standoff distance: 3.5 .

- When compared with the MOORA-PCA technique, the prediction accuracy of the TOPSIS-PCA hybrid approach model proved to be more acceptable.

The outcomes acquired in this work can be utilized as principles both scholasticresearch and modern applications. 
Table 4 Error calculation for MOORA-PCA vs. TOPSIS-PCA

\begin{tabular}{|c|c|c|c|c|c|c|}
\hline \multirow{2}{*}{ Exp. No. } & \multicolumn{3}{|c|}{ MOORA-PCA } & \multicolumn{3}{|c|}{ TOPSIS-PCA } \\
\hline & Experimental & Predicted & $\%$ error & Experimental & Predicted & $\%$ error \\
\hline 1 & 0.016 & 0.0150 & 6.25 & 0.770 & 0.560 & 0.5 \\
\hline 2 & -0.011 & 0.0099 & 9.92 & 0.794 & 0.683 & 0.9 \\
\hline 3 & 0.008 & 0.0070 & 12.5 & 0.770 & 0.560 & 0.5 \\
\hline 4 & 0.082 & 0.0816 & 0.46 & 0.739 & 0.287 & 0.8 \\
\hline 5 & 0.077 & 0.0710 & 7.79 & 0.746 & 0.600 & 2.8 \\
\hline 6 & 0.054 & 0.0510 & 5.56 & 0.757 & 0.440 & 0.1 \\
\hline 7 & 0.056 & 0.0540 & 3.57 & 0.762 & 0.627 & 2.4 \\
\hline 8 & -0.049 & 0.0460 & 6.12 & 0.794 & 0.548 & 1.8 \\
\hline 9 & -0.110 & 0.1000 & 9.09 & 0.779 & 0.582 & 1 \\
\hline 10 & -0.037 & 0.0380 & 2.7 & 0.793 & 0.739 & 1.3 \\
\hline 11 & -0.119 & 0.1110 & 6.72 & 0.762 & 0.590 & 2.6 \\
\hline 12 & 0.011 & 0.0111 & 1.14 & 0.795 & 0.774 & 2 \\
\hline 13 & 0.016 & 0.0140 & 12.5 & 0.769 & 0.688 & 0.3 \\
\hline 14 & 0.004 & 0.0039 & 2.500 & 0.775 & 0.667 & 1.6 \\
\hline 15 & 0.036 & 0.0340 & 5.56 & 0.762 & 0.551 & 0.1 \\
\hline 16 & 0.060 & 0.0580 & 3.33 & 0.761 & 0.596 & 0.3 \\
\hline 17 & 0.023 & 0.0221 & 3.8 & 0.779 & 0.667 & 0.3 \\
\hline 18 & -0.037 & 0.0350 & 5.41 & 0.805 & 0.596 & 1.4 \\
\hline 19 & -0.112 & 0.1100 & 1.79 & 0.765 & 0.414 & 1.5 \\
\hline 20 & 0.084 & 0.0860 & 2.38 & 0.748 & 0.704 & 0.6 \\
\hline 21 & 0.012 & 0.0128 & 6.67 & 0.781 & 0.560 & 0.9 \\
\hline 22 & 0.021 & 0.0202 & 3.81 & 0.769 & 0.618 & 0.4 \\
\hline 23 & -0.072 & 0.0690 & 4.17 & 0.806 & 0.635 & 1.3 \\
\hline 24 & -0.048 & 0.0420 & 12.5 & 0.788 & 0.535 & 1.7 \\
\hline 25 & 0.031 & 0.0300 & 3.23 & 0.771 & 0.432 & 1.7 \\
\hline 26 & -0.014 & 0.0130 & 7.14 & 0.776 & 0.618 & 0.3 \\
\hline \multirow[t]{2}{*}{27} & 0.057 & 0.0510 & 10.53 & 0.748 & 0.390 & 0.2 \\
\hline & Average error & & 5.82 & & 1.085 & \\
\hline
\end{tabular}

\section{References}

[1] Ranjan, R., Das, A. K. "Protection from corrosion and wear by different weld cladding techniques: A review", Materials Today: Proceedings, 2021.

https://doi.org/10.1016/j.matpr.2021.12.329

[2] Waghmare, D. T., Padhee, C. K., Prasad, R., Masanta, M. "NiTi coating on Ti-6Al-4V alloy by TIG cladding process for improvement of wear resistance: Microstructure evolution and mechanical performances", Journal of Materials Processing Technology, 262, pp. 551-561, 2018.

https://doi.org/10.1016/j.jmatprotec.2018.07.033

[3] Das, A. K., Kumar, S., Chaubey, M. K., Alam, W. "Tungsten Inert Gas (TIG) Cladding of TiC-Fe Metal Matrix Composite Coating on AISI 1020 Steel Substrate", Advanced Materials Research, 1159, pp. 19-26, 2020.

https://doi.org/10.4028/www.scientific.net/AMR.1159.19

[4] Singh, J., Thakur, L., Angra, S. "An investigation on the parameter optimization and abrasive wear behaviour of nanostructured WC-10Co-4Cr TIG weld cladding", Surface and Coatings Technology, 386, Article number: 125474, 2020. https://doi.org/10.1016/j.surfcoat.2020.125474
[5] Singh, J., Thakur, L., Angra, S. "Abrasive wear behavior of WC-10Co-4Cr cladding deposited by TIG welding process", International Journal of Refractory Metals and Hard Materials, 88, Article number: 105198, 2020.

https://doi.org/10.1016/j.ijrmhm.2020.105198

[6] Lima, C. R. C., Belém, M. J. X., Fals, H. D. C., Della Rovere, C. A. "Wear and corrosion performance of Stellite $6^{\circledR}$ coatings applied by HVOF spraying and GTAW hotwire cladding", Journal of Materials Processing Technology, 284, Article number: 116734, 2020. https://doi.org/10.1016/j.jmatprotec.2020.116734

[7] Kumar, A., Das, A. K. "Mechanical properties of Fe+SiC metal matrix composite fabricated on stainless steel 304 by TIG coating process", International Journal of Materials Engineering Innovation, 11(3), pp. 181-197, 2020. https://doi.org/10.1504/IJMATEI.2020.108880

[8] Tong, L. I., Wang, C. H., Chen, H. C. "Optimization of multiple responses using principal component analysis and technique for order preference by similarity to ideal solution", The International Journal of Advanced Manufacturing Technology, 27(3), pp. 407-414, 2005. https://doi.org/10.1007/s00170-004-2157-9 
[9] Sudhagar, S., Sakthivel, M., Mathew, P. J., Daniel, S. A. A. "A multi criteria decision making approach for process improvement in friction stir welding of aluminium alloy", Measurement, 108, pp. 1-8, 2017. https://doi.org/10.1016/j.measurement.2017.05.023

[10] Saha, A., Mondal, S. C. "Multi-objective optimization of manual metal arc welding process parameters for nano-structured hardfacing material using hybrid approach", Measurement, 102, pp. 80-89, 2017.

https://doi.org/10.1016/j.measurement.2017.01.048

[11] Majumder, H., Maity, K. "Optimization of Machining Condition in WEDM for Titanium Grade 6 Using MOORA Coupled with PCA - A Multivariate Hybrid Approach", Journal of Advanced Manufacturing Systems, 16(2), pp. 81-99, 2017. https://doi.org/10.1142/S0219686717500068

[12] Khan, A., Maity, K. P. "Parametric Optimization of Some NonConventional Machining Processes Using MOORA Method", International Journal of Engineering Research in Africa, 20, pp. 19-40, 2015. https://doi.org/10.4028/www.scientific.net/JERA.20.19

[13] Gadakh, V. S. "Application of MOORA method for parametric optimization of milling process", International Journal of Applied Engineering Research, Dindigul, 1(4), pp. 743-758, 2011.
[14] Majumder, H., Saha, A. "Application of MCDM based hybrid optimization tool during turning of ASTM A588", Decision Science Letters, 7(2), pp. 143-156, 2018.

https://doi.org/10.5267/j.ds1.2017.6.003

[15] Gadakh, V. S., Shinde, V. B., Khemnar, N. S. "Optimization of welding process parameters using MOORA method", The International Journal of Advanced Manufacturing Technology, 69(9), pp. 2031-2039, 2013.

https://oi.org/10.1007/s00170-013-5188-2

[16] Brauers, W. K., Zavadskas, E. K. "Robustness of the Multiobjective MOORA Method with a test for the Facilities Sector", Technological and Economic Development of Economy, 15(2), pp. 352-375, 2009 . https://doi.org/10.3846/1392-8619.2009.15.352-375

[17] Pearson, K. "LIII. On lines and planes of closest fit to systems of points in space", The London, Edinburgh, and Dublin Philosophical Magazine and Journal of Science, 2(11), pp. 559-572, 1901. https://doi.org/10.1080/14786440109462720 